\title{
Brain-Derived Neurotrophic Factor Modulates Intestinal Barrier by Inhibiting Intestinal Epithelial Cells Apoptosis in Mice
}

\author{
Dong-Yan ZHAO', Wen-Xue ZHANG ${ }^{2}$, Qing-Qing $\mathrm{QI}^{2}$, Xin LONG ${ }^{2}$, Xia $\mathrm{LI}^{2}$, Yan-Bo YU \\ Xiu-Li ZUO'
}

${ }^{1}$ Department of Gastroenterology, Puyang Oilfield General Hospital, Puyang, China, ${ }^{2}$ Department of Gastroenterology, Qilu Hospital, Shandong University, Jinan, China

Received March 29, 2017

Accepted December 15, 2017

On-line March 12, 2018

\section{Summary}

We aimed to investigate the effects of brain-derived neurotrophic factor (BDNF) on apoptosis of intestinal epithelial cells (IECS) and alterations of intestinal barrier integrity using BDNF knock-out mice model. Colonic tissues from $\mathrm{BDNF}^{+/+}$mice and $\mathrm{BDNF}^{+/-}$mice were prepared for this study. The integrity of colonic mucosa was evaluated by measuring trans-mucosa electrical resistance and tissue conductance in Ussing chamber. The colonic epithelial structure was analyzed by transmission electron microscopy. Apoptosis involvement was determined with TUNEL staining, active caspase- 3 immunostaining and Western blotting for the protein expression of active caspase-3, Bax and $\mathrm{Bcl}-2$. The expression levels and distribution of tight junction proteins were evaluated by immunohistochemistry or Western blots. Compared with $\mathrm{BDNF}^{+/+}$mice, $\mathrm{BDNF}^{+/}$mice displayed impaired integrity and ultrastructure alterations in their colonic mucosa, which was characterized by diminished microvilli, mitochondrial swelling and epithelial cells apoptosis. Altered intestinal barrier function was linked to excessive apoptosis of IECs demonstrated by the higher proportion of TUNEL-positive apoptotic cells and enhanced caspase activities in $\mathrm{BDNF}^{+/-}$mice. Increased expression of Bax and claudin-2 proteins and reduced $\mathrm{Bcl}-2$ and tight junction proteins (occludin, ZO-1 and claudin-1) expression were also detected in the colonic mucosa of $\mathrm{BDNF}^{+/-}$mice. BDNF may play a role in the maintenance of intestinal barrier integrity via its anti-apoptotic properties.

\section{Key words}

BDNF • Intestinal barrier • Intestinal epithelial cells • Apoptosis

\section{Corresponding author}

Y.-B. Yu, Department of Gastroenterology, Qilu Hospital, Shandong University, Jinan 250012, P.R. China. Fax: +86-53182166012. E-mail: yuyanbo2000@126.com

\section{Introduction}

Intestinal epithelial cells (IECs) play an important role in the maintenance of intestinal homeostasis. IECs provide a physiological barrier that prevents the entry of harmful antigens, microbes and allows nutrients and water transport from the intestinal lumen to the blood. Loss of epithelial integrity has been implicated as a critical factor in the predisposition to a number of gastrointestinal diseases, such as inflammatory bowel disease (IBD), irritable bowel syndrome (IBS) and celiac disease (Liu et al. 2011, Piche et al. 2009, Rauhavirta et al. 2014). Multiple mechanisms are responsible for maintaining the integrity of epithelial barrier (Jeon et al. 2013). Of note, growing evidence has demonstrated the important role of epithelial cell death by apoptosis in the regulation of barrier function (Sun et al. 1998, Zhang et al. 2002).

The balance between cell apoptosis and regeneration plays a critical role in the maintenance of intestinal integrity. Under physiological conditions, new epithelial cells are derived from stem cells in the crypt and then differentiate into mature forms to replace apoptotic cells shedding from the surface epithelial cuff (Gunther et al. 2013, Potten and Loeffler 1990). Spontaneous or induced excessive apoptosis of IECs can 
result in disruption of epithelial integrity and permeability defects during inflammatory, diet and infection-induced disease processes (Gunther et al. 2013). For example, patients suffering from IBD showed increased numbers of apoptotic IECs with corresponding barrier defects and the consequent translocation of bacteria into the intestinal wall (Maloy and Powrie 2011).

Preserving the integrity of the epithelial barrier by regulating the rate of cell death is considered crucial for maintaining intestinal homeostasis. A complex network of regulatory peptides, such as cyclooxygenase-2 (Fredenburgh et al. 2011), trefoil factor (Hanisch et al. 2017), glucocorticoids (Amsterdam et al. 2002) and transforming growth factor (TGF)- $\beta$ (Dignass and Podolsky 1993), have been identified as strong cytoprotective factors; thus, this factors play an important role in inhibiting apoptosis of IECs and mucosal defense. Brain-derived neurotrophic factor (BDNF), a member of the neurotrophin family, is originally known to play an important role in controlling cell survival, differentiation and death in the nervous system (Arevalo and $\mathrm{Wu} 2006$ ). An in vitro study indicated that the addition of BDNF could attenuate apoptosis induced by TNF- $\alpha$ and IFN- $\gamma$ in enteric glial cells (EGCs) (Steinkamp et al. 2012). In human vascular endothelial cells, BDNF maintains the integrity of blood vessel walls and avoids vascular leakage by protecting cells from apoptosis in response to inflammatory mediators (Matsuda et al. 2015, Takeda et al. 2013). In addition, BDNF is highly expressed in colorectal cancer compared with non-tumor tissues, and increased expression of BDNF can inhibit spontaneous cell apoptosis in tumorigenesis (Brunetto de Farias et al. 2010). These findings are further supported by another study in which genetic knock-out of BDNF in cultured colonic cells was associated with an increased rate of apoptosis and a decreased rate of cell growth (Yang et al. 2013). These studies raise the possibility that BDNF may play a vital role in the regulation of enterocyte apoptosis. As is known, BDNF has been confirmed expressed in the gut mucosa of various species, including humans and mice (Chen et al. 2012, Yu et al. 2012). It has been demonstrated that immunoreactions to BDNF are highly up-regulated in colonic biopsies taken from patients suffering from Crohn's disease and ulcerative colitis (Johansson et al. 2007, Steinkamp et al. 2012). Besides, massive apoptosis of colonocytes have been demonstrated in patients suffering from IBD, which could cause the focal disruption of epithelial integrity (Di Sabatino et al. 2003, Gitter et al. 2001). However, whether BDNF is involved in the regulation of epithelial barrier function by affecting apoptosis of intestinal epithelial cells remains unknown.

The purpose of the present study was to investigate the effects of BDNF on apoptosis of IECs and alterations of intestinal barrier integrity using a BDNF knock-out mouse model. We also evaluate possible related molecules involved in BDNF induced apoptosis of IECs. Heterozygous mice $\left(\mathrm{BDNF}^{+/}\right)$were used in this study because a previous study demonstrated that homozygous mice $\left(\mathrm{BDNF}^{-/}\right)$mice would develop sensory deficits, severe respiratory problems, and die within 3 weeks after birth (Erickson et al. 1996).

\section{Methods}

Animals

Five heterozygous male $\mathrm{BDNF}^{+/-}$mice and wild-type male $\mathrm{BDNF}^{+++}$littermates were generous gifts from the Neurobiology Laboratory of Shandong University. The line of $\mathrm{BDNF}^{+/-}$mice generated as described previously was maintained on a $\mathrm{C} 57 \mathrm{BL} / 6$ genetic background by backcrossing for 15-18 generations (Ernfors et al. 1994). The animals were housed under conditions of controlled temperature $\left(21 \pm 1^{\circ} \mathrm{C}\right)$, humidity $(50 \pm 5 \%)$ and lighting (12-h day/12-h night). All experiments were performed with adult mice that were 4 months of age. Experimental protocols were approved by the Animal Care and Use Committee of Shandong University, and were conducted in accordance with the guidelines of Chinese Institutional Animal Care Committee.

\section{Tissue processing}

After an overnight fast, mice were sacrificed by cervical dislocation. For each mouse, five colonic segments of approximately $1 \mathrm{~cm}$ in length were prepared. One segment of distal colon was processed for further TUNEL analysis and immunohistochemistry. One segment of distal colon was fixed for electron microscopy observation. Two segments of proximal colon were removed for Ussing chamber experiments. For the final segment of proximal colon, colonic mucosa was obtained by blunt stripping from muscularis and serosa and then snap frozen in liquid nitrogen and stored at $-80{ }^{\circ} \mathrm{C}$ for further Western blotting analyses.

\section{Ussing chamber experiments}

Segments of the proximal colon were opened along the mesenteric border. The serosa layer and 
muscularis layer were carefully removed under an inverted microscope. The murine colon tissue was then mounted in Ussing chambers (Physiologic Instruments, San Diego, CA) with an exposed tissue area of $0.3 \mathrm{~cm}^{2}$. After mounting, each side of chambers was filled with $5 \mathrm{ml}$ of preheated $37^{\circ} \mathrm{C}$ Krebs buffer, and continuously oxygenated with $95 \% \mathrm{O}_{2}$ and $5 \% \mathrm{CO}_{2}$. After 15 min of equilibration, voltage changes were recorded continuously for $60 \mathrm{~min}$ followed by intermittent current pulses of $0.001 \mathrm{~mA}$. Trans-mucosa electrical resistance (TER, $\left.\Omega / \mathrm{cm}^{2}\right)$ and tissue conductance $\left(\mathrm{S} / \mathrm{cm}^{2}\right)$ were calculated from the spontaneous potential difference and short-circuit current according to Ohm's law by using the software of Acquire and analyze 2.3. The values of TER and tissue conductance are the mean value of the two segments, with a calculated individual coefficient of variability $<5 \%$.

\section{Transmission electron microscopy (TEM)}

Colonic segments for TEM were immediately fixed in a cacodylate-buffered $2.5 \%$ glutaraldehyde solution at $4{ }^{\circ} \mathrm{C}$ overnight, washed in cacodylate buffer $(0.1 \mathrm{~mol} / \mathrm{l})$, and postfixed with $1 \%$ osmium tetroxide for $1 \mathrm{~h}$ at room temperature. After washing in cacodylate buffer $(0.1 \mathrm{~mol} / \mathrm{l})$, the samples were dehydrated in graded concentrations of acetone, and embedded in Araldite. Samples were cut into semithin sections $(500 \mathrm{~nm})$ with an ultramicrotome equipped with a glass knife while ultrathin sections $(70 \mathrm{~nm})$ were cut on the same microtome equipped with a diamond knife. Toluidine blue-stained semithin sections were screened under an optical microscope to observe colonic epithelial layers. Following this, ultrathin sections were double stained with uranyl acetate and lead citrate, and observed under a JEOL CX1200 electron microscope.

\section{Immunohistochemistry}

Colonic segments from $\mathrm{BDNF}^{+/-}$mice and $\mathrm{BDNF}^{+/+}$mice were fixed in $10 \%$ neutral buffered formalin. Immunohistological studies were performed on paraffin-embedded $4-\mu \mathrm{m}$ thick sections. The sections were heated in boiling Tris-ethylenediaminetetraacetic acid (0.01 M, pH 6.0) for $15 \mathrm{~min}$ in a microwave oven and endogenous peroxidase activity was blocked by $3 \%$ hydrogen peroxide (Rabbit SP kit, Zhongshan Gold Bridge, Beijing, China). Following antigen unmasking, sections were incubated overnight at $4{ }^{\circ} \mathrm{C}$ with rabbit anti-active-caspase- 3 antibody (1:300, Abcam, Cambridge, UK), rabbit anti ZO-1 antibody (1:500,
Invitrogen, CA, USA) and rabbit anti-occludin antibody (1:500, Santa Cruz Biotechnology, Santa Cruz, CA, USA). The sections were then washed in phosphatebuffered saline (PBS) and incubated at room temperature for $2 \mathrm{~h}$ with anti-rabbit secondary antibody (Rabbit SP kit, Zhongshan Gold Bridge, Beijing, China) according to the manufacturer's instructions. Diaminobenzidine (DAB) was used as the chromogen, followed by counterstained with haematoxylin and viewed under a light microscope (Olympus Bx51). To provide a negative control, the same procedure was performed with the omission of primary or secondary antibodies.

Occludin and ZO-1-immunoreactive areas per square millimeter of mucosa were quantified in at least five representative non-overlapping high power fields (HPFs) at $\times 400$ magnification by using the Image-Pro Plus 6.0 software (Media Cybernetics, Silver Spring, Maryland, USA). For tight junction proteins analysis, the immunostaining was measured by the integrated optical density (IOD) with the above software, and the results were expressed as IOD/sum stained area to indicate the mean intensity of staining, which represented the expression levels of tight junction proteins.

\section{Labeling of apoptotic cells}

Apoptotic colonic epithelial cells were labeled in situ by identifying DNA fragmentation on paraffin embedded sections using the terminal deoxynucleotidyl transferase UTP nick end labeling (TUNEL) assay (Roche, Mannheim, Germany). The criteria for identifying apoptotic cells included condensation of chromatin, brown-stained nuclei and formation of a surrounding halo. The rate of apoptosis was calculated as the ratio of TUNEL-positive cells to the total number of cells counted. This comprised of formal counting of the number of TUNEL-positive cells present within 5 random high power fields of intestinal epithelial cells (>150 enterocytes/field).

\section{Western blotting analysis}

Colonic tissue was homogenized in RIPA buffer containing protease inhibitors (Zhongshan Gold Bridge, Beijing, China). The tissue extract was subject to centrifuge at $12,000 \mathrm{rpm}$ for $20 \mathrm{~min}$ at $4{ }^{\circ} \mathrm{C}$. Protein concentrations were determined using a BCA Protein Assay kit (Solarbio, Beijing, China). Total protein was added to a loading buffer and boiled for $10 \mathrm{~min}$ until fully denatured.

Proteins were separated and electrotransferred 
to polyvinylidene difluoride membranes (Bio-Rad, Hercules, USA). The membranes were incubated at $4{ }^{\circ} \mathrm{C}$ overnight with rabbit polyclonal anti-BDNF antibody (1:500, Abcam, Cambridge, UK), rabbit polyclonal anti-active caspase-3 antibody (1:300, Abcam, Cambridge, UK), rabbit monoclonal anti-Bcl-2 antibody (1:1,000, Abcam, Cambridge, UK), rabbit monoclonal anti-Bax antibody (1:1,000, Abcam, Cambridge, UK), mouse anti-claudin-1 antibody (1:500, Invitrogen, CA, USA) or mouse anti-claudin-2 antibody (1:500, Invitrogen, CA, USA). After washing by Tris-buffered saline containing $0.1 \%$ Tween- 20 (TBST) three times, the membranes were subsequently incubated with HRP-conjugated goat anti-rabbit secondary antibody (1:1,000, Zhongshan Gold Bridge, Beijing, China) at room temperature for $1 \mathrm{~h}$. The bands were detected by using the enhanced chemiluminescence technique (Amersham, Buckinghamshire, UK) on Kodak BioMax light film. Chemiluminescent signals of protein bands were quantified by ImageJ compared to $\beta$-actin band density (1:10,000, Zhongshan Gold Bridge, Beijing, China).

\section{Statistical analysis}

All values are expressed as the means $\pm \mathrm{SEM}$. Statistical analyses were conducted using SPSS 20.0 (SPSS, Chicago, IL, USA). Significance of differences between $\mathrm{BDNF}^{+/+}$mice and $\mathrm{BDNF}^{+/}$mice was evaluated by the two-tailed Student's t-tests. Spearman rank correlations were applied for correlation analyses between TER and colonic apoptotic rate. Data were considered statistically significant when $\mathrm{P}<0.05$.

\section{Ethics approval and consent to participate}

Experimental protocols were approved by the Animal Care and Use Committee of Shandong University, and were conducted in accordance with the guidelines of Chinese Institutional Animal Care Committee.

\section{Results}

\section{Colonic mucosal BDNF level}

The levels of BDNF in colonic mucosa were significantly reduced in $\mathrm{BDNF}^{+/-}$mice compared with $\mathrm{BDNF}^{+/+}$mice (Fig. 1A). And the levels of BDNF were reduced by approximately half in transgenic mice ( $83.93 \pm 9.74 \%$ vs. $49.23 \pm 7.36 \%, \mathrm{P}=0.031$ ) (Fig. 1B).

\section{Colonic mucosal integrity}

The integrity of colonic mucosa in $\mathrm{BDNF}^{+/}$mice was evaluated by measuring TER and tissue conductance in Ussing chambers. The TER values were significantly lower in $\mathrm{BDNF}^{+/-}$mice than in $\mathrm{BDNF}^{+/+}$mice $\left(141.77 \pm 11.13 \Omega / \mathrm{cm}^{2}\right.$ vs. $\left.82.74 \pm 10.60 \Omega / \mathrm{cm}^{2}, \mathrm{P}=0.005\right)$, and the conductance was greater in $\mathrm{BDNF}^{+/}$mice $\left(0.0075 \pm 0.0007 \mathrm{~m} / \mathrm{cm}^{2} \quad\right.$ vs. $0.0130 \pm 0.0018 \mathrm{~m} / \mathrm{cm}^{2}$, $\mathrm{P}=0.004)$, suggesting that $\mathrm{BDNF}^{+-}$mice displayed impaired colonic mucosal integrity (Figs 1C and 1D).
A

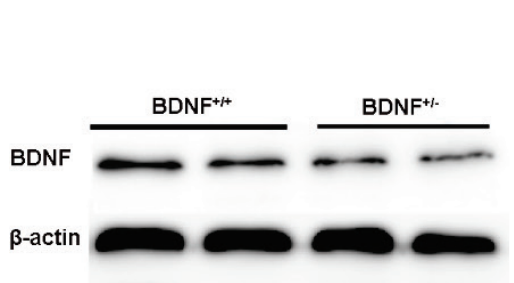

B

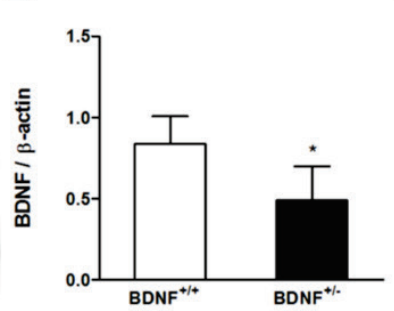

C

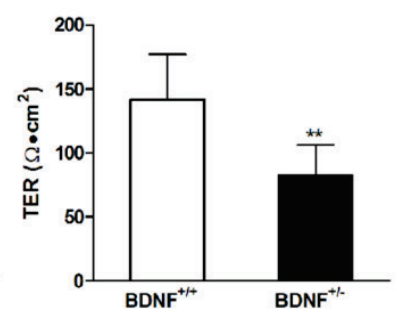

D

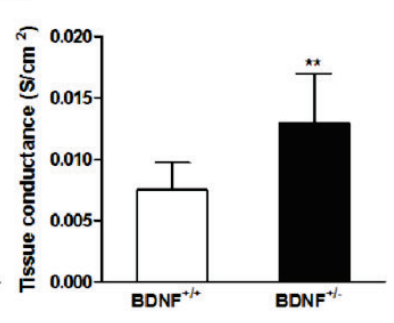

Fig. 1. Representative immunoblots (A) and densitometric analyses of BDNF levels (B) in the colonic mucosa of BDNF ${ }^{+/+}$mice and $\mathrm{BDNF}^{+-}$mice. (C, D) The integrity of colonic mucosa in $\mathrm{BDNF}^{+/+}$mice and $\mathrm{BDNF}^{+/-}$mice was evaluated by measuring TER and tissue conductance in Ussing chambers. $* \mathrm{P}<0.05$. $* * \mathrm{P}<0.01$. $\mathrm{n}=5$ per group. TER, trans-mucosa electrical resistance.

\section{Ultrastructural findings of the colonic epithelium}

We performed ultrastructural analyses to further evaluate the mucosal integrity of $\mathrm{BDNF}^{+/}$mice. The colonic epithelium of $\mathrm{BDNF}^{+/+}$mice consisted of regular columnar cells with numerous apical microvilli on the apical surface of the cell (Fig. 2A). The epithelial cells exhibited a central and elongated nucleus featuring prominent euchromatin and a cluster of heterochromatin on the edge (Fig. 3A). The electron-dense cytoplasm presented homogeneous content with numerous transparent vesicles and rounded mitochondria with well-developed and observable cristae (Figs 3A and 3C).

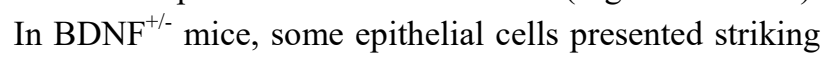
changes of their ultrastructure, including diminished or partially disappeared microvilli, less electron-dense cytoplasm (Fig. 3D), an increased number of vacuolated 
vesicles (Fig. 2B), swollen mitochondria with disrupted or blurred cristae (Fig. 3D). Besides, the nuclei became irregularly condensed, pyknotic and featured a predominant of heterochromatin compared with $\mathrm{BDNF}^{+/+}$mice (Fig. 3B). Some vacuoles containing cytoplasmic constituents, cell granules and apoptotic bodies were blebbing from the cytoplasm (Fig. 3E). Also, the less electron-dense cytoplasm, apoptotic bodies (Fig. 2B) and the condensed nuclei (Fig. 3B) indicated apoptosis of colonic epithelial cells in $\mathrm{BDNF}^{+-}$mice. In some samples, the apical part of the intercellular junction complex between two adjacent epithelial cells was damaged with widen intercellular space (Fig. 2C).
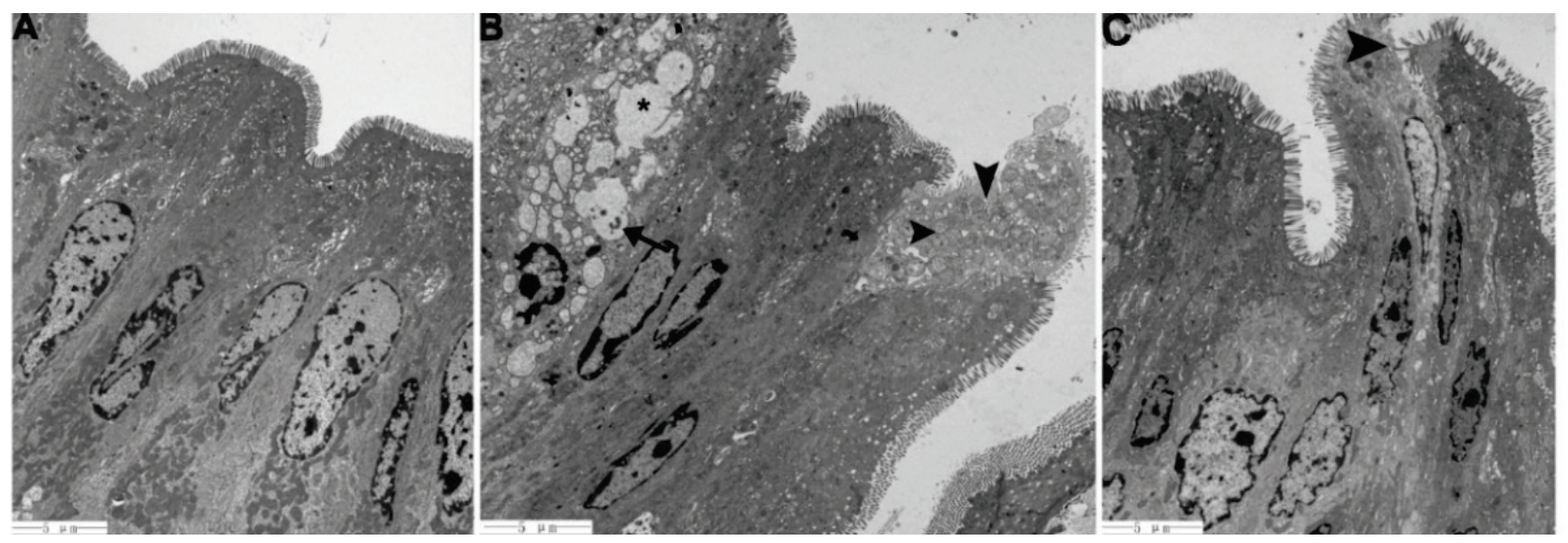

Fig. 2. Ultrastructural features of apoptosis in the colonic mucosa of $\mathrm{BDNF}^{+/-}$mice (B). The colonic epithelium of $\mathrm{BDNF}^{+/+}$mice consisted of regular columnar cells with numerous apical microvilli on the plasma membrane $(\mathbf{A})$. The apoptotic cells were readily detected in the colonic mucosa of $\mathrm{BDNF}^{+-}$mice (B). The ultrastructure of apoptotic cells was characterized by vacuolated cytoplasm (asterisk), apoptotic bodies (arrow) and degenerated cell organelles (arrowhead). (C) The apical part of intercellular junction complex was partly disrupted (arrowhead).

\section{Apoptosis and caspase-3 activation in $\mathrm{BDNF}^{+/}$mice}

TUNEL staining, as well as immunohistochemistry and Western blots for active caspase-3 were carried out for further supporting apoptosis of colonic epithelial cells in $\mathrm{BDNF}^{+/-}$mice. For $\mathrm{BDNF}^{+/-}$mice, TUNEL-positive labeled epithelial cells were scattered in both the cuff and the crypt of the colonic epithelium (Fig. 4A). However, no positive staining was found in the crypt of the epithelium in $\mathrm{BDNF}^{+/+}$mice (Fig. 4A). By image analysis, the proportion of TUNEL-positive cells was significantly increased in the colonic epithelium of $\mathrm{BDNF}^{+/-}$mice compared with $\mathrm{BDNF}^{+/+}$mice $(9.28 \pm 0.60 \%$ vs. $34.70 \pm 1.44 \%, \quad \mathrm{P}<0.001) \quad$ (Fig. $4 \mathrm{~A})$. Besides, a statistical correlation was drawn between the apoptotic rate and TER of colonic segments in $\mathrm{BDNF}^{+/+}$ mice and $\mathrm{BDNF}^{+/}$mice ( $\left.\mathrm{rs}=-0.70, \quad \mathrm{P}=0.024\right)$. By immunostaining, colonic epithelial cells of $\mathrm{BDNF}^{+/-}$mice exhibited positive immunolabeling for active caspase- 3 (Fig. 4B). Similarly, Western blot analyses demonstrated that the expression levels of active caspase- 3 in colonic epithelium were significantly elevated in the $\mathrm{BDNF}^{+/}$ mice than in $\mathrm{BDNF}^{++}$mice $(24.12 \pm 9.57 \%$ vs. $70.48 \pm 8.25 \%, \mathrm{P}=0.007$ ) (Fig. 4B).

\section{Apoptosis-related proteins levels in colonic mucosa}

The expression levels of apoptosis-related proteins were investigated by Western blot. Compared with $\mathrm{BDNF}^{+/+}$mice, the protein levels of $\mathrm{Bcl}-2$ in the colonic epithelium of $\mathrm{BDNF}^{+/-}$mice were significantly reduced $(70.01 \pm 10.68 \%$ vs. $38.41 \pm 4.91 \%, \quad \mathrm{P}=0.023)$, while the protein levels of Bax were remarkably increased in $\mathrm{BDNF}^{+/}$mice $(21.53 \pm 7.11 \%$ vs. $70.70 \pm 10.91 \%, \mathrm{P}=0.009$ ) (Fig. $5 \mathrm{~A}$ ). Consequently, the ratio of $\mathrm{Bcl}-2 / \mathrm{Bax}$ in the colonic mucosa was significantly decreased in $\mathrm{BDNF}^{+/-}$mice compared with $\mathrm{BDNF}^{+/+}$mice $(1.89 \pm 0.16$ vs. $0.99 \pm 0.24, \mathrm{P}=0.036)$.

Tight junction protein expression levels in $B D N F^{+/}$mice

Occludin- and ZO-1-like immunoreactivity was seen abundantly distributed throughout the mucosa in $\mathrm{BDNF}^{+/+}$mice. Quantification revealed that the expression levels of occludin and ZO-1 in the colonic mucosa were significantly lower in $\mathrm{BDNF}^{+/}$mice than in controls (occludin, $37.86 \pm 4.60$ vs. $22.24 \pm 2.18, \mathrm{P}=0.015$; $\mathrm{ZO}-1,39.77 \pm 4.57$ vs. $22.28 \pm 2.98, \mathrm{P}=0.012$ ) (Fig. $5 \mathrm{~B}$ ). Claudin-1 protein levels were significantly decreased $(143.37 \pm 10.74 \%$ vs. $106.72 \pm 6.48 \%, \mathrm{P}=0.019)$ whereas claudin-2 protein levels were significantly increased 


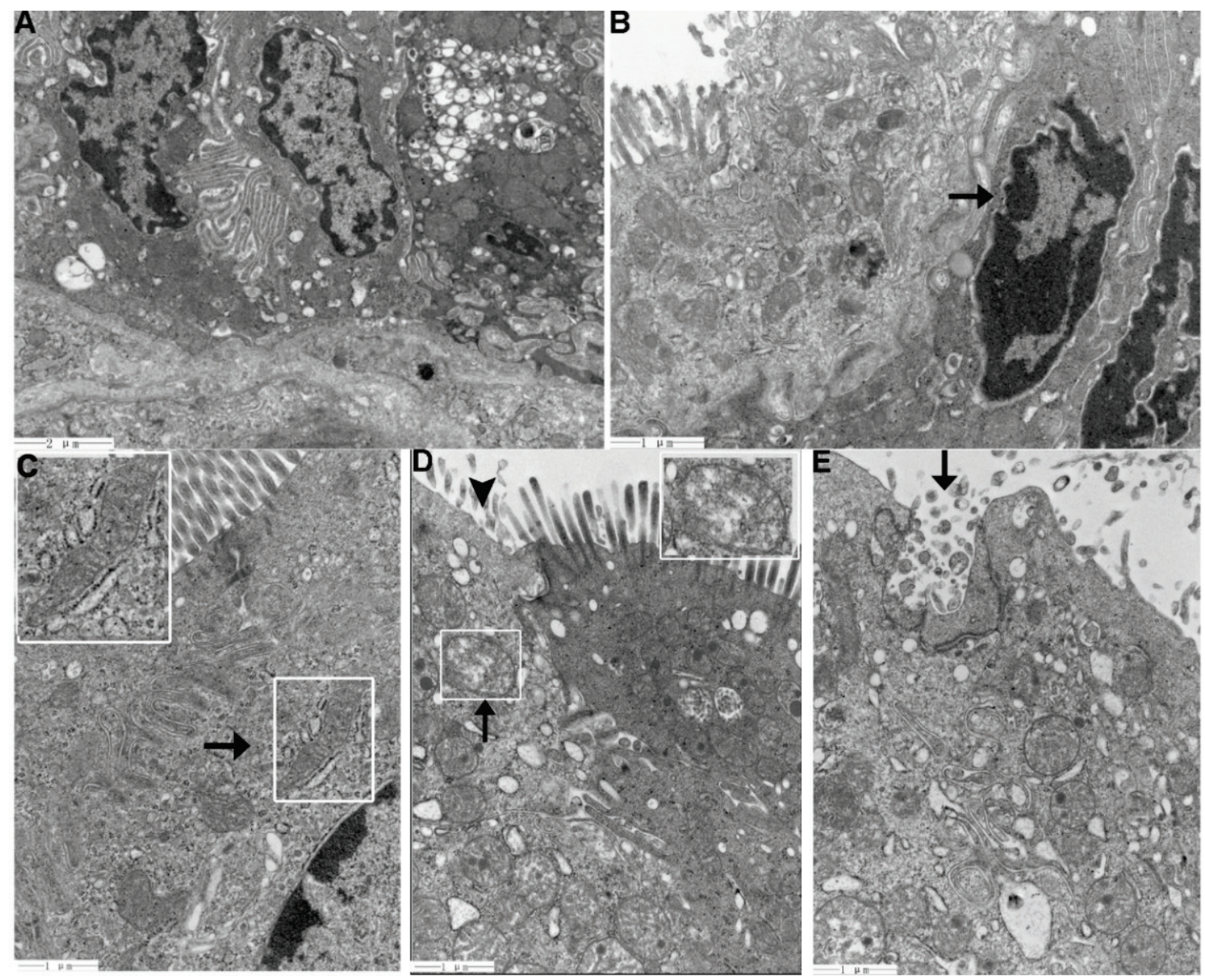

Fig. 3. Ultrastructural features of the epithelial cells in $\mathrm{BDNF}^{+/+}$mice $(\mathbf{A}, \mathbf{C})$ and $\mathrm{BDNF}^{+/-}$mice $(\mathbf{B}, \mathbf{D}$ and $\mathbf{E})$. Normal cell nucleus $(\mathbf{A})$ and mitochondria structure (arrow in $\mathbf{C}$ ) was presented in the epithelium cells of $\mathrm{BDNF}^{+/+}$mice. Damage in $\mathrm{BDNF}^{+/-}$mice was demonstrated by less electron-dense cytoplasm, condensation and margination of nuclear chromatin (arrow in B), swelling mitochondria with blurred cristae (arrow in D) and rarefied microvilli (arrowhead in D). Some vacuoles containing cytoplasmic constituents, cell granules and apoptotic bodies were blebbing from the cytoplasm in $\mathrm{BDNF}^{+-}$mice (arrow in E).

$(88.40 \pm 9.76 \%$ vs. $140.72 \pm 12.77 \%, \mathrm{P}=0.012)$ in the intestinal mucosa of $\mathrm{BDNF}^{+/-}$mice compared to control mice.

\section{Discussion}

In the present study, we showed for the first time that BDNF deficiency could contribute to intestinal integrity defects in mice, which was illustrated by ultrastructural examinations in $\mathrm{BDNF}^{+/-}$mice. These BDNF-mediated epithelial integrity alterations were further confirmed to be associated with excessive apoptosis of IECs demonstrated by a higher proportion of TUNEL-positive epithelial cells and increased active caspase-3 expression levels. These findings indicated that BDNF might play a role in the maintenance of intestinal barrier integrity via its anti-apoptotic properties.

As is known, a single layer of intestinal epithelial cells covers the surface of intestine and provides the first line of barrier against luminal antigens.
The structural integrity of the intestine and physiological gut homeostasis are only maintained by the rate of cell apoptosis matching the rate of cell renewal (Wong et al. 1999). Thus, apoptosis is a critical step responsible for maintaining the integrity of the intestinal mucosal epithelium. In our study, ultrastructural examinations revealed for the first time that barrier damages existed in the colonic mucosa of $\mathrm{BDNF}^{+/}$mice, which was demonstrated by diminished membrane microvilli, mitochondrial swelling and increased epithelial cells apoptosis. These data raised the possibility that BDNF might inhibit epithelial cell apoptosis and maintain the integrity of the intestine barrier.

BDNF has been reported to be widely expressed in the nervous system. Earlier studies demonstrated that among neurotrophins, BDNF is predominantly involved in neuron proliferation, survival and differentiation (Huang and Reichardt 2001). BDNF has drawn recent attention because of its critical role in non-nervous system. For example, increased expression levels of 
BDNF have been reported in non-nervous system tumors, such as colorectal cancer (Tanaka et al. 2014), choriocarcinoma (Kawamura et al. 2013), myeloma (Chu et al. 2013), pancreatic cancer (Sclabas et al. 2005) and bladder cancer (Lai et al. 2010). Moreover, BDNF has the potential for inhibiting endothelial cells apoptosis and modulating endothelial barrier function in the process of periodontal tissue regeneration (Matsuda et al. 2015). Farias et al (2010) reported that BDNF could protect HT-29 human colonic cells from death in response to cetuximab, which had inhibitory effects on cell proliferation and survival.

A
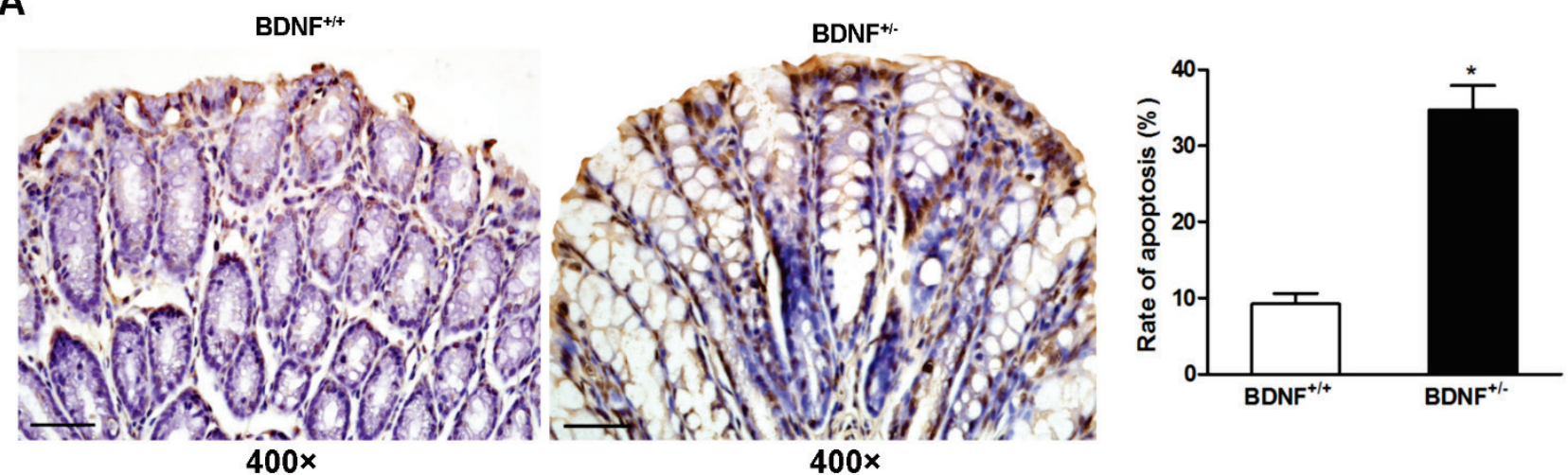

\section{B}
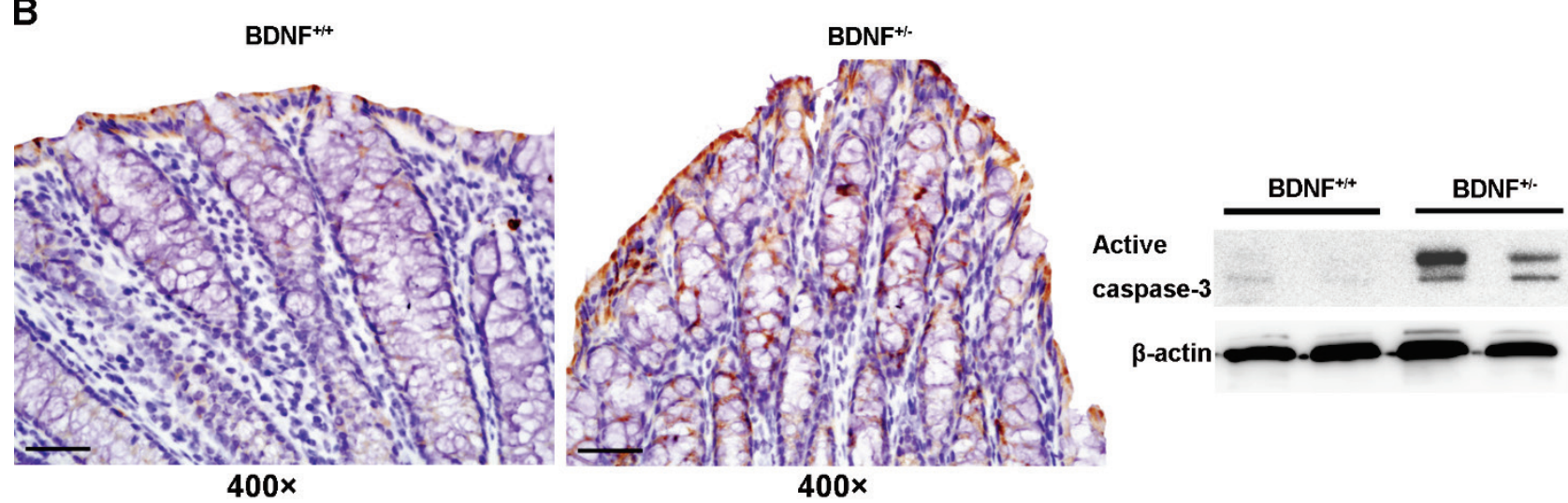

Fig. 4. (A) Comparisons of TUNEL staining of the colonic mucosa between $\mathrm{BDNF}^{+/+}$mice and $\mathrm{BDNF}^{+/-}$mice. Quantification of TUNEL-positive cells in the colonic mucosa. ${ }^{*} \mathrm{P}<0.001$. $\mathrm{n}=5$ per group. Scale bar, $100 \mu \mathrm{m}$. (B) Active caspase-3 expression in the colonic mucosa. Representative micrographs showing active caspase- 3 immunoreactivity in the colonic section of BDNF $^{+/+}$mice and $\mathrm{BDNF}^{+/-}$mice. Scale bar, $100 \mu \mathrm{m}$.

In this study, using genetic knock-out mice, we specifically addressed the role of BDNF on the apoptosis of intestinal epithelial cells in vivo. TEM study revealed that epithelial cells in $\mathrm{BDNF}^{+/-}$mice demonstrated cytoplasmic hypervacuolization, nuclear chromatin condensation and apoptotic body formation, which were representative signs for apoptosis. TUNEL staining results showed that $\mathrm{BDNF}^{+/}$mice exhibited an increased number of apoptotic cells in the colonic mucosa. A significant negative correlation was further drawn between TER measured in Ussing chamber and the apoptosis ratio of the IECs. These data suggested that altered intestinal barrier function in $\mathrm{BDNF}^{+/}$mice was associated with excessive apoptosis of IECs. It should be noted that TUNEL method not only recognizes apoptosis, but also labels cell death by necrosis (Grasl-Kraupp et al. 1995, Otsuki et al. 2003). Several cells with characteristics of necroptosis were also observed by TEM. That is, showing extensive vacuole formation, mitochondrial swelling and degenerated organelles. To further identify the type of cell death, we performed immunohistochemistry (IHC) for active caspase-3. Caspase- 3 is a ubiquitously distributed key player in the terminal pathway of apoptosis, and its activation has been demonstrated to occur together with the characteristic morphological changes that are the hallmarks of apoptosis (Earnshaw et al. 1999). In concordance with TUNEL results, we showed that the expression levels of 
active caspase-3 in the colonic epithelium were significantly higher in the $\mathrm{BDNF}^{+/-}$mice than in $\mathrm{BDNF}^{+/+}$ mice. Moreover, $\mathrm{BDNF}^{+/-}$mice demonstrated a marked down-regulation of tight junction proteins, including occludin, ZO-1 and claudin-1 and a marked up-regulation of claudin- 2 in the colonic mucosa, which fitted well with ultrastructural alterations of junction complex found by TEM. It is well known that intestinal barrier function is regulated by IECs and intercellular junction complexes in which tight junction is the major constituent (Balda and Matter 2008, Groschwitz and Hogan 2009). All of these findings indicated that BDNF deficiency might lead to excessive apoptosis of IECs in $\mathrm{BDNF}^{+/-}$mice, resulting in the disruption of epithelial barrier. Similar results were also obtained in our previous study ( $\mathrm{Yu}$ et al. 2017). BDNF knockdown in colonic epithelial cell lines reduced the expression of tight junction proteins, providing clear evidence that BDNF can regulate intestinal barrier integrity in vitro. It should be noted that claudin-2 was up-regulated in the colon of $\mathrm{BDNF}^{+/}$mice. In contrast, our previous study showed that claudin-2 protein were significantly decreased in the HT-29 cell line after BDNF knockdown in vitro (Yu et al. 2017). Occludin, ZO-1 and claudin-1 strengthen the barrier and reduce permeability, whereas claudin-2 has been related to cation-selective channel activity and increased permeability (Amasheh et al. 2002, Zhang et al. 2013). It is unclear how BDNF regulate the expression of claudin-2 in vivo. Further studies should be performed to elucidate the precise mechanisms of their interactions. Although tight junction dysregulation is usually thought of as a downstream consequence of excessive IECs death in the epithelial mucosa, several studies have demonstrated that the tight junctions occludin and ZO-1 have signaling properties that activate the pathway of programmed cell death (Beeman et al. 2012, Beeman et al. 2009). It remains unclear whether increased IECs death is a secondary event caused by disrupted tight junctions or whether it is a causative event contributing to tight junction dysregulation in genetic mouse models. This needs to be further evaluated.
A
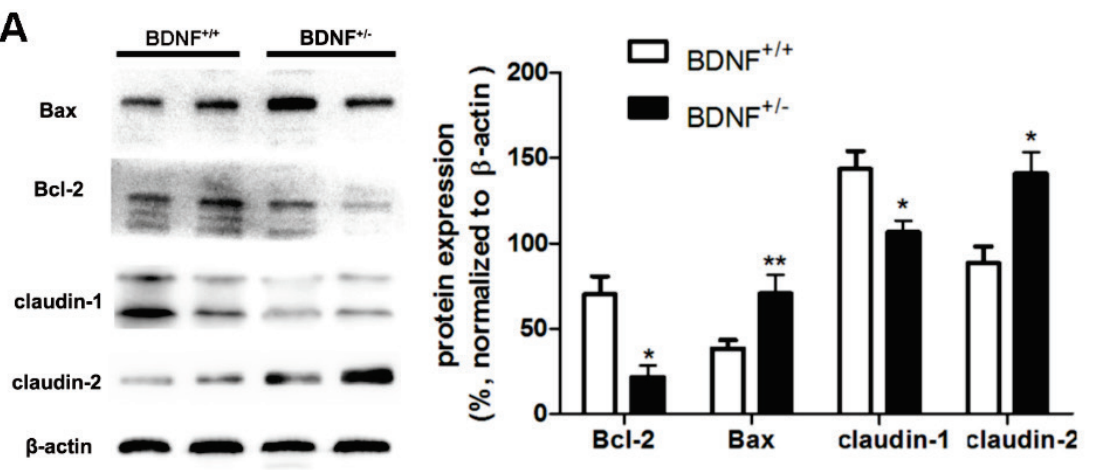

B
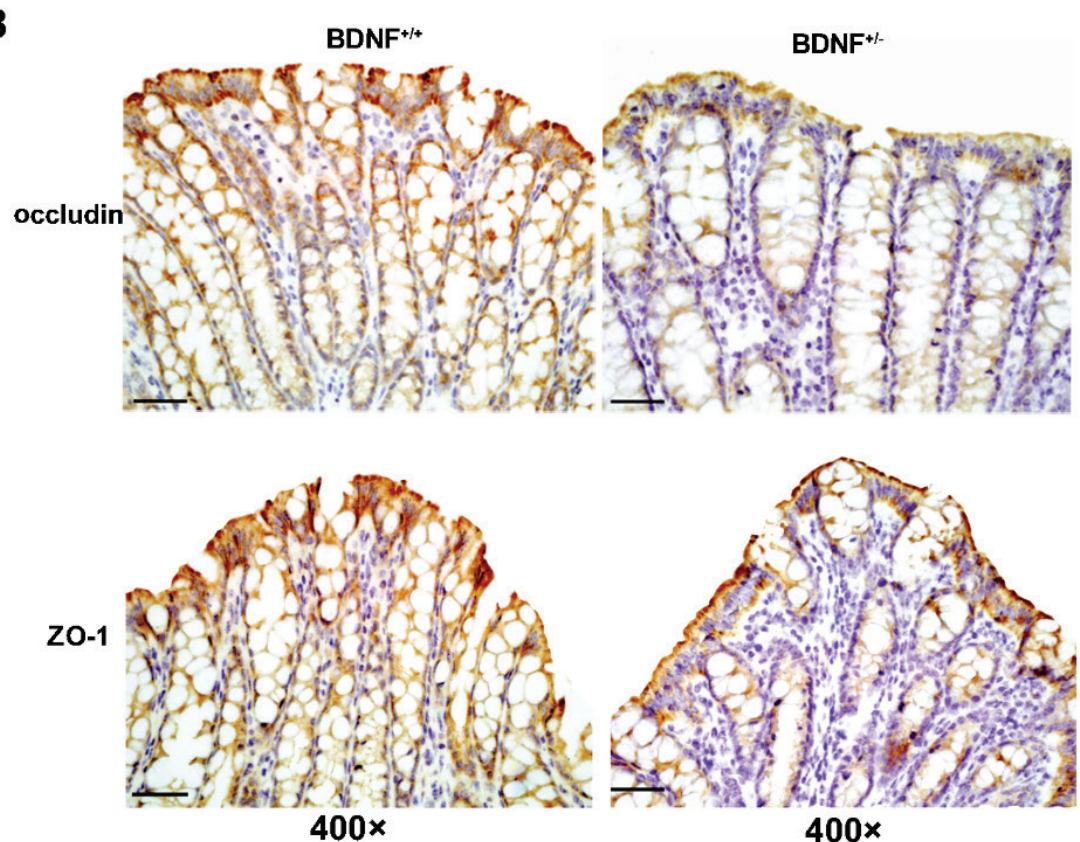

$400 x$

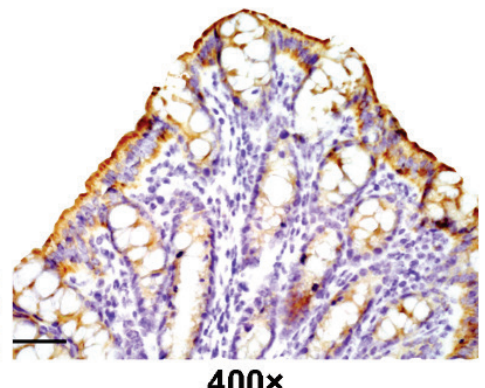

Fig. 5. (A) Representative immunoblots and densitometric analyses of Bcl-2, Bax, claudin-1 and claudin-2 in the colonic mucosa of $\mathrm{BDNF}^{+/+}$mice and $\mathrm{BDNF}^{+/-}$mice. $* \mathrm{P}<0.05, * * \mathrm{P}<0.01$. $\mathrm{n}=5$ per group. (B) Representative micrographs showing occluding and ZO-1 immuno-reactivity in the colonic section of $\mathrm{BDNF}^{+/+}$mice and $\mathrm{BDNF}^{+/-}$ mice. Scale bar, $100 \mu \mathrm{m}$. 
To investigate the processes underlying our observations of excessive apoptosis of IECs in the colonic mucosa of $\mathrm{BDNF}^{+/-}$mice, we investigated the expression of apoptosis-related proteins (Bcl-2 and Bax). In normal cells, the pro-survival Bcl-2 proteins keep the integrity of mitochondrial membrane and defend cell from death by inhibiting the activation of the pro-apoptotic Bax proteins. The Bcl-2/Bax ratio plays an important role in determining the fate of cells (Delbridge and Strasser 2015, Hale et al. 1996). In our study, the protein levels of Bcl-2 were significantly decreased while the activity of Bax protein were markedly enhanced in the colonic mucosa of $\mathrm{BDNF}^{+/-}$ mice compared with control mice. In line with our results, one recent study reported the decreased Bcl-2 expression in the BDNF knocked-down human colonic cells (Yang et al. 2013). Besides, a decreased Bcl-2/Bax ratio revealed the impaired ability to protect IECs from apoptosis in $\mathrm{BDNF}^{+/-}$mice. Taken together, our data indicated that BDNF might inhibit apoptosis of IECs by affecting Bcl-2/Bax ratio.

There are several limitations of this study. First, the expressions of BDNF in other structural parts, such as enteric nervous system (ENS), were not evaluated in this study. In addition, the potential role of BDNF in the regulation of intestinal epithelial barrier by activating ENS signaling should be further investigated. Second, we focused on the expression of BDNF in only the proximal colon. However, there is variation in the expression levels of BDNF in different segments of gastrointestinal tract in mice (Lommatzsch et al. 1999). Lastly, fluorescein isothiocyanate (FITC)-dextran assays were not used to examine intestinal permeability in the present study. Other quantitative measurements should be used to examine the expression of occludin and ZO-1.

In summary, $\mathrm{BDNF}^{+/-}$mice were characterized by an increased number of apoptotic IECs with corresponding barrier defects in the colonic mucosa. These observations demonstrate the role of BDNF in the maintenance of intestinal epithelial barrier function via its anti-apoptotic properties. The underlying mechanism through which BDNF inhibits apoptosis may be due to its regulation of the balance between $\mathrm{Bcl}-2$ and Bax. Understanding the detailed modulation of intestinal barrier integrity by BDNF may provide new insights into the management of apoptosis-related intestinal inflammatory diseases.

\section{Conflict of Interest}

There is no conflict of interest.

\section{Acknowledgements}

The authors appreciate the considerable assistance from the Key Laboratory of Cardiovascular Remodeling and Function Research in Qilu Hospital of Shandong University. This work was supported by the National Natural Science Foundation of China (NSFC 81670486) and The Fundamental Research Funds of Shandong University (2017JC036).

\section{References}

AMASHEH S, MEIRI N, GITTER AH, SCHONEBERG T, MANKERTZ J, SCHULZKE JD, FROMM M: Claudin-2 expression induces cation-selective channels in tight junctions of epithelial cells. J Cell Sci 115: 4969-4976, 2002.

AMSTERDAM A, TAJIMA K, SASSON R: Cell-specific regulation of apoptosis by glucocorticoids: implication to their anti-inflammatory action. Biochem Pharmacol 64: 843-850, 2002.

AREVALO JC, WU SH: Neurotrophin signaling: many exciting surprises! Cell Mol Life Sci 63: 1523-1537, 2006.

BALDA MS, MATTER K: Tight junctions at a glance. J Cell Sci 121: 3677-3682, 2008.

BEEMAN N, WEBB PG, BAUMGARTNER HK: Occludin is required for apoptosis when claudin-claudin interactions are disrupted. Cell Death Dis 3: e273, 2012.

BEEMAN NE, BAUMGARTNER HK, WEBB PG, SCHAACK JB, NEVILLE MC: Disruption of occludin function in polarized epithelial cells activates the extrinsic pathway of apoptosis leading to cell extrusion without loss of transepithelial resistance. BMC Cell Biol 10: 85, 2009.

BRUNETTO DE FARIAS C, ROSEMBERG DB, HEINEN TE, KOEHLER-SANTOS P, ABUJAMRA AL, KAPCZINSKI F, BRUNETTO AL, ASHTON-PROLLA P, MEURER L, REIS BOGO M, DAMIN DC, SCHWARTSMANN G, ROESLER R: BDNF/TrkB content and interaction with gastrin-releasing peptide receptor blockade in colorectal cancer. Oncology 79: 430-439, 2010. 
CHEN FX, YU YB, YUAN XM, ZUO XL, LI YQ: Brain-derived neurotrophic factor enhances the contraction of intestinal muscle strips induced by SP and CGRP in mice. Regul Pept 178: 86-94, 2012.

CHU ZB, SUN CY, YANG D, CHEN L, HU Y: Role of brain-derived neurotrophic factor in bone marrow angiogenesis in multiple myeloma. J Huazhong Univ Sci Technolog Med Sci 33: 485-490, 2013.

DELBRIDGE AR, STRASSER A: The BCL-2 protein family, BH3-mimetics and cancer therapy. Cell Death Differ 22: 1071-1080, 2015.

Di SABATINO A, CICCOCIOPPO R, LUINETTI O, RICEVUTI L, MORERA R, CIFONE MG, SOLCIA E, CORAZZA GR: Increased enterocyte apoptosis in inflamed areas of Crohn's disease. Dis Colon Rectum 46: 1498-1507, 2003.

DIGNASS AU, PODOLSKY DK: Cytokine modulation of intestinal epithelial cell restitution: central role of transforming growth factor beta. Gastroenterology 105: 1323-1332, 1993.

EARNSHAW WC, MARTINS LM, KAUFMANN SH: Mammalian caspases: structure, activation, substrates, and functions during apoptosis. Аnпи Rev Biochem 68: 383-424, 1999.

ERICKSON JT, CONOVER JC, BORDAY V, CHAMPAGNAT J, BARBACID M, YANCOPOULOS G, KATZ DM: Mice lacking brain-derived neurotrophic factor exhibit visceral sensory neuron losses distinct from mice lacking NT4 and display a severe developmental deficit in control of breathing. J Neurosci 16: 5361-5371, 1996.

ERNFORS P, LEE KF, JAENISCH R: Mice lacking brain-derived neurotrophic factor develop with sensory deficits. Nature 368: 147-150, 1994.

FREDENBURGH LE, VELANDIA MM, MA J, OLSZAK T, CERNADAS M, ENGLERT JA, CHUNG SW, LIU X, BEGAY C, PADERA RF, BLUMBERG RS, WALSH SR, BARON RM, PERRELLA MA: Cyclooxygenase-2 deficiency leads to intestinal barrier dysfunction and increased mortality during polymicrobial sepsis. J Immunol 187: 5255-5267, 2011.

GITTER AH, WULLSTEIN F, FROMM M, SCHULZKE JD: Epithelial barrier defects in ulcerative colitis: characterization and quantification by electrophysiological imaging. Gastroenterology 121: 1320-1328, 2001.

GRASL-KRAUPP B, RUTTKAY-NEDECKY B, KOUDELKA H, BUKOWSKA K, BURSCH W, SCHULTE-HERMANN R: In situ detection of fragmented DNA (TUNEL assay) fails to discriminate among apoptosis, necrosis, and autolytic cell death: a cautionary note. Hepatology 21: 1465-1468, 1995.

GROSCHWITZ KR, HOGAN SP: Intestinal barrier function: molecular regulation and disease pathogenesis. $J$ Allergy Clin Immunol 124: 3-20; quiz 21-22, 2009.

GUNTHER C, NEUMANN H, NEURATH MF, BECKER C: Apoptosis, necrosis and necroptosis: cell death regulation in the intestinal epithelium. Gut 62: 1062-1071, 2013.

HALE AJ, SMITH CA, SUTHERLAND LC, STONEMAN VE, LONGTHORNE V, CULHANE AC, WILLIAMS GT: Apoptosis: molecular regulation of cell death. Eur J Biochem 237: 884, 1996.

HANISCH C, SHARBATI J, KUTZ-LOHROFF B, HUBER O: Trefoil factor 3 mediates resistance to apoptosis in colon carcinoma cells by a regulatory RNA axis. Cell Death Dis 8: e2660, 2017.

HUANG EJ, REICHARDT LF: Neurotrophins: roles in neuronal development and function. Annu Rev Neurosci 24: 677-736, 2001.

JEON MK, KLAUS C, KAEMMERER E, GASSLER N: Intestinal barrier: Molecular pathways and modifiers. World J Gastrointest Pathophysiol 4: 94-99, 2013.

JOHANSSON M, NORRGARD O, FORSGREN S: Study of expression patterns and levels of neurotrophins and neurotrophin receptors in ulcerative colitis. Inflamm Bowel Dis 13: 398-409, 2007.

KAWAMURA K, KAWAMURA N, OKAMOTO N, MANABE M: Suppression of choriocarcinoma invasion and metastasis following blockade of BDNF/TrkB signaling. Cancer Med 2: 849-861, 2013.

LAI PC, CHIU TH, HUANG YT: Overexpression of BDNF and TrkB in human bladder cancer specimens. Oncol Rep 24: 1265-1270, 2010.

LIU JJ, MADSEN KL, BOULANGER P, DIELEMAN LA, MEDDINGS J, FEDORAK RN: Mind the gaps: confocal endomicroscopy showed increased density of small bowel epithelial gaps in inflammatory bowel disease. J Clin Gastroenterol 45: 240-245, 2011. 
LOMMATZSCH M, BRAUN A, MANNSFELDT A, BOTCHKAREV VA, BOTCHKAREVA NV, PAUS R, FISCHER A, LEWIN GR, RENZ H: Abundant production of brain-derived neurotrophic factor by adult visceral epithelia. Implications for paracrine and target-derived Neurotrophic functions. Am J Pathol 155: 1183-1193, 1999.

MALOY KJ, POWRIE F: Intestinal homeostasis and its breakdown in inflammatory bowel disease. Nature 474: 298-306, 2011.

MATSUDA S, FUJITA T, KAJIYA M, KASHIWAI K, TAKEDA K, SHIBA H, KURIHARA H: Brain-derived neurotrophic factor prevents the endothelial barrier dysfunction induced by interleukin-1beta and tumor necrosis factor-alpha. J Periodontal Res 50: 444-451, 2015.

OTSUKI Y, LI Z, SHIBATA MA: Apoptotic detection methods--from morphology to gene. Prog Histochem Cytochem 38: 275-339, 2003.

PICHE T, BARBARA G, AUBERT P, BRULEY DES VARANNES S, DAINESE R, NANO JL, CREMON C, STANGHELLINI V, DE GIORGIO R, GALMICHE JP, NEUNLIST M: Impaired intestinal barrier integrity in the colon of patients with irritable bowel syndrome: involvement of soluble mediators. Gut 58: 196-201, 2009.

POTTEN CS, LOEFFLER M: Stem cells: attributes, cycles, spirals, pitfalls and uncertainties. Lessons for and from the crypt. Development 110: 1001-1020, 1990.

RAUHAVIRTA T, LINDFORS K, KOSKINEN O, LAURILA K, KURPPA K, SAAVALAINEN P, MAKI M, COLLIN P, KAUKINEN K: Impaired epithelial integrity in the duodenal mucosa in early stages of celiac disease. Transl Res 164: 223-231, 2014.

SCLABAS GM, FUJIOKA S, SCHMIDT C, LI Z, FREDERICK WA, YANG W, YOKOI K, EVANS DB, ABBRUZZESE JL, HESS KR, ZHANG W, FIDLER IJ, CHIAO PJ: Overexpression of tropomysin-related kinase B in metastatic human pancreatic cancer cells. Clin Cancer Res 11: 440-449, 2005.

STEINKAMP M, SCHULTE N, SPANIOL U, PFLUGER C, HARTMANN C, KIRSCH J, VON BOYEN GB: Brain derived neurotrophic factor inhibits apoptosis in enteric glia during gut inflammation. Med Sci Monit 18: BR117-BR122, 2012.

SUN Z, WANG X, WALLEN R, DENG X, DU X, HALLBERG E, ANDERSSON R: The influence of apoptosis on intestinal barrier integrity in rats. Scand J Gastroenterol 33: 415-422, 1998.

TAKEDA K, KERMANI P, ANASTASIA A, OBINATA Y, HEMPSTEAD BL, KURIHARA H: BDNF protects human vascular endothelial cells from TNFalpha-induced apoptosis. Biochem Cell Biol 91: 341-349, 2013.

TANAKA K, OKUGAWA Y, TOIYAMA Y, INOUE Y, SAIGUSA S, KAWAMURA M, ARAKI T, UCHIDA K, MOHRI Y, KUSUNOKI M: Brain-derived neurotrophic factor (BDNF)-induced tropomyosin-related kinase B (Trk B) signaling is a potential therapeutic target for peritoneal carcinomatosis arising from colorectal cancer. PLoS One 9: e96410, 2014.

WONG MH, STAPPENBECK TS, GORDON JI: Living and commuting in intestinal crypts. Gastroenterology 116: 208-210, 1999.

YANG X, MARTIN TA, JIANG WG: Biological influence of brain-derived neurotrophic factor (BDNF) on colon cancer cells. Exp Ther Med 6: 1475-1481, 2013.

YU YB, ZHAO DY, QI QQ, LONG X, LI X, CHEN FX, ZUO XL: BDNF modulates intestinal barrier integrity through regulating the expression of tight junction proteins. Neurogastroenterol Motil 29: e12967, 2017.

YU YB, ZUO XL, ZHAO QJ, CHEN FX, YANG J, DONG YY, WANG P, LI YQ: Brain-derived neurotrophic factor contributes to abdominal pain in irritable bowel syndrome. Gut 61: 685-694, 2012.

ZHANG C, SHENG ZY, HU S, GAO JC, YU S, LIU Y: The influence of apoptosis of mucosal epithelial cells on intestinal barrier integrity after scald in rats. Burns 28: 731-737, 2002.

ZHANG YG, WU S, XIA Y, SUN J: Salmonella infection upregulates the leaky protein claudin-2 in intestinal epithelial cells. PLoS One 8: e58606, 2013. 